anywhere - neither to Antarctica or Africa, nor to Central or North America. A land link was only re-established within the past 5 million years. Thus throughout almost the entire Cenozoic era it was in splendid isolation, receiving only periodic mammal invasions by waif dispersal from some other continent(s). The history of the faunas is retailed in three phases: the earliest faunas of the Palaeocene and Eocene have just three basic stocks (the marsupials, xenarthrans and condylarths); in the second phase during the Oligocene and Miocene, we witness the addition of rodents and primates; and the third phase begins in the early Pliocene (as defined by Simpson) with the build-up to the great American interchange of mammal faunas north-south across the continents. The book finishes with a summary chapter and a note on the restoration of extinct animals.

The book is highly factual and, as we would expect of the doyen, highly accurate and up-to-date with the latest fossil discoveries. But the facts are too often dry and indigestible. Accounts of each family with descriptions of their dental characteristics do not make easy reading, the more so as few are adequately illustrated. Indeed the illustrations are almost totally limited to elemental reconstructions - all without scale. The Plio-Pleistocene and Recent faunas are very summarily treated; much of the space here is devoted to etymological discourse. Simpson's penchant for both logodaedaly and sesquipedality are evident throughout. There are no photographs, no skeletal reconstructions and only one palaeogeographical map - and that of the midCretaceous. Palaeogeography is a subject to which the author has himself made signal contributions, yet it is all but ignored in this book; it merits space only in the last three pages. Considering the tremendous impact of plate tectonics theory over the past decade, much could have been said, if only in summary, about the continent's history and its relationships to adjacent regions during the past 80 million years. The author tells us his first and second phase colonizations were waif dispersals. The centre(s) of origin of waifs has been the subject of copious debate; Simpson, fairly but very briefly, disposes of the arguments on the grounds that we have too few facts to come to definitive conclusions. The third phase colonization is certainly better documented, but Simpson refuses to be drawn into the current debates on palaeogeographical models, dispersal or vicariance - the latter originating with a Venezuelan biologist. Many scientists feel such models are useful in that they offer a challenge to discover adequate evidence to test a hypothesis. With the immense knowledge and unique experience Simpson possesses, we would all appreciate and profit from having his palaeogeographical interpretation. For without this, the history is as Hamlet without the Prince of
Denmark. The task may be, to use Simpson's words, Herculean, but it is hardly Sisyphean.

There is no recent work with which Splendid Isolation can readily be compared. Patterson and Pascual's brilliant essay review of 1972, "The Fossil Mammal Fauna of South America"' (In Evolution, Mammals and Southern Continents, edited by A. Keast et al. State University

\section{Suspending time: a guide for biologists}

\section{David E. Pegg}

Low Temperature Preservation in Medicine and Biology. Edited by M.J. Ashwood-Smith and J. Farrant. Pp.323. (Pitman Medical: Tunbridge Wells, UK/University Park Press: Baltimore, 1980.) $£ 17.50, \$ 39.50$.

WHEN Polge, Smith and Parkes made the discovery, in 1948, that glycerol would enable avian spermatozoa to survive freezing at $-79^{\circ} \mathrm{C}$, they could scarcely have anticipated the impact their observation was to have in medicine and biology. The special value of preserving viable cells in the deep-frozen state is that this essentially suspends time: chemical reactions are arrested and even the recrystallization of ice is prevented at the generally used storage temperature of $-196^{\circ} \mathrm{C}$, the boiling point of nitrogen. Then, only ionizing radiation can produce damage, but as Ashwood-Smith points out in this book, it would take 32,000 years to accumulate a dose of 600 rads! The cryobiologists' trick then is to cool cells to, and recover them from, $-196^{\circ} \mathrm{C}$ without damage. Although the conditions necessary to achieve this differ widely from cell to cell, remarkable successes have been achieved: nowadays, innumerable scientists and technicians in fields as disparate as clinical blood banking, animal husbandry, immunology, reference culture collection of bacterial, fungal, animal and plant cells, and entomology use cryopreservation as a tool in their daily work, perhaps with little knowledge of the principles upon which the techniques are based. This book sets out to provide a guide for such workers.

Farrant opens the book with a delightfully clear elementary explanation of mechanisms of freezing injury and cryoprotection. Ashwood-Smith then describes current techniques for the preservation of tissue culture cells and some mammalian tissues, and Polge, truly one of the founders of cryobiology, contributes an excellent chapter on the development of techniques for the cryopreservation of spermatozoa - full of practical detail, but of New York Press: Albany), is still indispensable to the serious student. Yet, while the balance of topics treated in Splendid Isolation is sometimes too light and sometimes too heavy, there is much a student will find interesting in this curious history.

R.J.G. Savage is Reader in Vertebrate Palaeontology at the University of Bristol, UK.

also interestingly reflective on the way in which this field has developed. Whittingham gives excellent guidance from his wide personal experience of the low temperature preservation of early embryos of many mammals. The chapters on haematological applications, by Rowe and Schaefer, are essentially practical and detailed, while Knight provides an admirable critical account of work on the preservation of leukocytes, emphasizing the difficulties of obtaining valid measurements of post-thaw recovery. The chapters on protozoa and helminth parasites by James, on micro-organisms by AshwoodSmith and on plant cells by Morris are all clear and packed with practical advice, while the contribution by Ring on the cryobiology of insects and their cells is particularly fascinating and goes beyond practical preservation to describe the fascinatingly varied adaptations found in insects that survive the extremely low temperatures occurring in Arctic regions. The book concludes with a chapter of general practical guidance.

Without doubt, this will prove to be a valuable text: it is not, however, as comprehensive as its title might suggest. Low temperatures, but without freezing, arc widely used in medicine and biology for the short-term preservation of cells, tissues and organs, most importantly perhaps of blood cells for transfusion and of tissues and organs for transplantation. None of this is dealt with. Moreover the excellent introductory chapter could, I believe, usefully be supplemented by a more detailed discussion of theoretical cryobiology to help the reader digest the mass of 'cookbook' detail found in the subsequent chapters. Also, the balance of contributors seems a little strange in that it does not reflect the major contribution of workers in the USA during the past 20 years. Finally, the chapter on practical aspects would be much improved by the inclusion of greater detail of the actual equipment and procedures being discussed. (The thermocouple table on p.290 differs from the current BSI and NBS standards.) These arc relatively small details, however, and the editors can be congratulated on a most useful compilation: perhaps they will consider widening the scope of future editions.

David E. Pegg is head of the MRC Medical Cryobiology Group in the Department of Surgery, University of Cambridge, UK. 